\title{
DOCUMENTOS
}

\section{EL TESTAMENTO DEL PINTOR ANTONIO DE TORRES}

\author{
Mina Ramírez Montes
}

La búsqueda continua de materiales documentales que nos permitan esclarecer la historia del arte colonial mexicano, me puso ahora en las huellas que dejara Antonio de Torres. Este pintor nació, según Francisco de la Maza, en 1666.' Fue natural y vecino de la ciudad de México, hijo de Tomás de Torres y Lorenzana y de María Rodríguez, seguramente hermana del pintor Antonio Rodríguez y tía de los hermanos Rodríguez Juárez, pues entre los albaceas que nombra el artífice que nos ocupa, se encuentra el pintor Juan Rodríguez Juárez, a quien menciona como su primo.

Antonio de Torres casó en primeras nupcias con Inés de Córdova y Priego, según De la Maza en 1693. De la fecha no hay seguridad, pues mis pesquisas en los archivos parroquiales del Sagrario metropolitano y de la Santa Veracruz no tuvieron éxito; en este último era probable que hubiese algún dato, ya que el artista perteneció a esa parroquia por haber vivido en el barrio de San Juan de la Penitencia. Supongo que Francisco de la Maza tomó esa fecha de la obra Historia de la pintura en Puebla, cuyo autor la tomó a su vez de El arte en Nueva España de Díez Barroso, donde se habla de un pintor homónimo y contemporáneo, hijo de Francisco Valdés y Torres, casado en Puebla el dos de marzo de $1693 .{ }^{2}$ En ctanto a las obras pictóricas de cada uno, habrá que deslindarlas en el futuro, tal vez por su respectivo estilo.

El pintor que ahora nos ocupa debe ser el autor de varias series de vidas ejemplares: la del santo de Asís para la iglesia de San Francisco en San Luis Potosí, firmada en 1719, y la de san Felipe Neri para los padres del Oratorio, hoy en la pinacoteca de La Profesa de esta metrópoli, no como afirma Xavier Moyssén ${ }^{2 a}$ que ambas series se encuentran en la ciudad de

' Francisco de la Maza, El atte colonial en San Luis Potosí, 2a. ed., México, Instituto de Investigaciones Estéticas, UNAM, 1985, p. 46.

${ }^{2}$ Ibidem, Apud. Francisco Pérez de Salazar, Historia de la pintura en Puebla. Introd. de Elisa Vargas Lugo, México, Instituto de Investigaciones Estéticas, UNAM, 1963, p. 211; Francisco Díez Barroso, El arte en Nueva España, (s e.), 1921. En la obra de Agustín Velázquez Chávez, Tres siglos de pintura colonial mexicana, México, Editorial Polis, 1939, p. 133, se fusionan los datos conocidos de ambos pintores.

2a Xavier Moyssén. "La pintura en el siglo XVIIT", Historia del arte mexicano, 2a. ed., México, SEP Salvat, 1986, v. 8, p. 1068. 
México. Hay otros lienzos de Torres en La Profesa: una Purísima y dos escenas de la vida de san Francisco Xavier.

Las pinturas firmadas por Antonio de Torres se encuentran diseminadas por varios lugares del país: en San Luis Potosí, en San Miguel de Allende, en Dolores Hidalgo, en Metztitlán, en Guadalajara, en Zacatecas, en Aguascalientes, en Acolman y en la ciudad de México; en esta última, además de las citadas, en el Museo Nacional de Historia, en la catedral, en la iglesia de San Diego en Churubusco y en la de la Gualupita; en el colegio de las Vizcaínas y en colecciones oficiales y privadas. ${ }^{3}$

El autor de este testamento y el poseedor de los bienes que mencionaremos, creo yo, que es el pintor de todos esos cuadros firmados con la rúbrica Antonio de Torres y que se encuentran en los lugares arriba entumerados; considero que sus relaciones familiares con el gremio a que perteneció, en especial con Antonio Rodríguez e hijos, de quienes pudo haber sido discípulo y condiscípulo respectivamente, le llevaron a ser contratado infinidad de veces por eclesiásticos y particulares. Tal debió haber sido su fama que fue invitado, junto con otros pintores, a examinar el lienzo de la Guadalupana en $1721 .^{4}$

Llevó a cabo varios avalúos de pinturas: en 1711, las que pertenecieron a Pedro de Vergara; en 1713, los cuadros de Juan de Valdés; en 1724 apreció los de Miguel de Pedraza y en 1727 los de don Carlos y su mujer. ${ }^{5}$

Antonio de Torres testó el 13 de octubre de 1722 porque se encontraba quebrantado de salud; sin embargo, se recuperó bien de aquellos achaques; no así su mujer, que pronto murió y lo dejó libre para contraer nuevas nupcias. Su segundo matrimonio debió de realizarse hacia 1724, esta vez con María Millán, de quien no tuvo descendencia. A la muerte de Antonio, acaecida siete años después, ${ }^{6}$ María Millán entregó a su hijastra Inés de Torres, viuda de Pedro de Zúñiga y Rivero, los bienes que quedaron de su padre; éstos, al igual que el testamento, los incluimos textualmente por conside-

${ }^{3}$ F. de la Maza, op. cit, p. 46; Abelardo Carrillo y Gariel, Autógrafos de pintores coloniales, México, Instituto de Investigaciones Estéticas, UNAM, 1953, p. 144-166; Archivo Histórico del Instituto de Investigaciones Estéticas, Colección Abelardo Carrillo y Gariel, exp. 44, fs. 325-326 y exp. 250, fs. 2909-2914, y Manuel Toussaint, pintura colonial, 2a ed., México, Instituto de Investigaciones Estéticas, UNAM, 1982, p. 147.

4 Bernardo Couto, Diálogo sobre bistoria de la pintura en México, México, Fondo de Cultura Económica, 1947, p. 86.

${ }^{5}$ M. Toussaint, op. cit., p. 155 y A. Carrillo y G. op. cit., p. 144, publican la rúbrica del avalúo de los bienes de Pedraza (4 de octubre de 1724), la cual es igual a la de su testamento.

${ }^{6} \mathrm{Op}$. cit., v. 8, p. 1068, dice que no se conoce la fecha precisa de su muerte, pero afirma que fue después de 1738. Por el recibo que otorgó Inés de Torres a su madrasta en 6 de agosto de 1731, sabemos que murió en ese año. 
rar ambos documentos de gran interés para la historia de la pintura novohispana.

Entre sus bienes se cuentan los materiales propios de su oficio: paletas de pintor, pinceles, caballetes, batidores, vasijas para moler y mezclar pigmentos, reglas, varas de medir y balanzas, lienzos, tablas, colas, colores, carbones, oro falso y toda clase de herramientas útiles. Además, libros, estampas, perfiles, imágenes de bulto -algunas en blanco que seguramente pretendía pintar, dorar y encarnar-, un lienzo de santa Bárbara que dejó bosquejado; unos tableros para un retablo que le encargaron los indios, no aclara de dónde, sólo que el colateral lo tenía un dorador de Chiconautla. Parece ser que recibía muchos encargos, cuyas cuentas anotaba en libros: el de los españoles y el de los indios. A todo esto hay que añadir el menaje de su casa y los lienzos de devoción que la decoraban.

No es de mi competencia analizar lo diestro de su pincel; tampoco su técnica ni la evolución de su estilo; pero al observar la mayoría de sus pinturas autografiadas, no puedo menos que expresar que hay algo en común en ellas y que bien pueden servir estos datos como un peldaño más para su estudio.

\section{TESTAMENTO}

En el nombre de Dios nuestro Señor todopoderoso amén. Notorio y manifiesto sea a todos los que el presente vieren, como yo don Antonio de Torres, maestro del arte de pintor, natural y originario de esta ciudad de México, hijo legítimo de don Tomás de Thorres y Lorenzana y de doña María Rodríguez, difuntos. Estando en pie, aunque con algunos achaques habituales, en mi entero juicio, cumplida memoria y entendimiento natural, creyendo como firmemente creo, el altísimo misterio de la Santísima Trinidad, padre, hijo y espiritu santo, tres personas distintas y un solo Dios verdadero y el soberano misterio de la encarnación del Verbo eterno en las purísimas y virginales entrañas de la reina de los ângeles, la virgen santa María nuestra Señora, concebida sin la culpa original en el primer instante de sú ser y todos los demás misterios y sacramentos que tiene, cree y confiesa, predica y enseña nuestra santa madre Iglesia católica, apostólica, romana, debajo de cuya fe y creencia declaro haber vivido y protesto vivir y morir como católico y fiel cristiano, eligiendo por mis auxiliares patronos y abogados a la siempre virgen María madre de Dios y Señora nuestra, al glorioso patriarca señor san José, su purísimo esposo, al santo ángel de mi guarda, santo de mi nombre y demás de mi devoción, para que en la divina presencia pidan y alcancen de nuestro Señor Jesucristo, el que mis pecados sean perdonados y mi ánima sea puesta en carrera de salvación, en temiéndome de la muerte y lo incierto de su hora, en su prevención otorgo y hago y ordeno mi testamento y última voluntad, en la forma y manera siguiente: 
Primeramente encomiendo mi alma a Dios nuestro Señor que la crió y redimió con el infinito mérito de su preciosa sangre, pasión y muerte y el cuerpo a la tierra de que fue formada, el cual siendo fallecido, quiero sea sepultado en la iglesia, capilla, parte y lugar que pareciere a mis albaceas, a cuya disposición lo dejo con lo demás de mi funeral y entierro;

Mando a las mandas forzosas y acostumbradas dos tomines a 'cada una, otros dos para ayuda a la canonización del glorioso san Felipe de Jesús, otros dos para la del venerable siervo de Dios, Gregorio López y otros dos para la de la venerable madre María de Jesús de Agreda, cuyas limosnas se paguen de mis bienes, con que las aparto de ellos.

Item. Declaro soy tercero de hábito descubierto de nuestro seráfico Padre san Francisco y he sido conciliario de su venerable mesa y asimismo soy congregante de otras congregaciones, como parecerá de las patentes que paran en su poder, ordeno se avise para que cumplan con su obligación, por haber yo cumplido con la mía.

Item. Declaro soy casado y velado, según orden de nuestra santa madre Iglesia, con doña Inés de Córdova, hija legítima de don Diego de Córdova y de doña María de Priego, y al tiempo y cuando contrajimos matrimonio, trajo a mi poder por su caudal y dote lo que consta por el recibo que a su favor otorgué, como asimismo lo que yo le mandé en arras, al cual me remito. $Y$ durante nuestro matrimonio hemos habido y procreado por nuestra hija legítima a doña Inés de Torres, la cual se halla casada y velada con don Pedro de Súñiga y Rivero, declárolo así para que conste. Item. Declaro que cuando casé y puse en estado a la dicha doña Inés de Torres, mi hija, con el dicho don Pedro de Súñiga y Rivero, no le dí en reales cosa alguna, solo sí en ajuar de casa y ropa para su decencia, como cantidad de ciento y cincuenta pesos, poco más o menos, y algunos años después le di unas pulseras de perlas que me costaron doscientos pesos y otros cincuenta y cinco que me costaron otras perlas para gargantilla, lo cual declaro para que conste.

Item. Declaro por mis bienes una casa entresolada de fábrica de adobe, en el barrio de san Juan de la Penitencia y callejón que llaman de San José, la cual compré en cantidad de cien pesos y para la reedificación de ella gasté cantidad de trescientos pesos y se hallan libres de censo, hipoteca, ni otra enajenación, como todo lo referido consta de los títulos que paran en mi poder a que me remito.

Item. Declaro que en poder del dicho don Pedro de Súñiga y Rivero, para la cantidad de cien pesos, resto de doscientos que tenía entregados, para efectó de que los impusiese sobre unas casitas que el susodicho posée y ha labrado en esta ciudad, en la plazuela de San Juan, con obligación de réditos de un cinco por ciento y con los diez pesos de ellos se cantase una misa anualmente a Nuestra Señora de Guadalupe, de la cofradía que se halla fundada en la iglesia del convento de religiosas de San Juan de la Penitencia, y respecto a que el dicho don Pedro me dió y pagó cien pesos y sólo para en su poder el resto de dichos cien pesos, quiero y es mi voluntad que de lo mejor y más bien parado de mis bienes se saque la cantidad de cien pesos, que juntos con los otros ciento que tiene en su poder el dicho don Pedro, mi hijo, que hacen la de doscientos, los imponga 
el suso dicho a censo redimible sobre sus casas, si quisiera o sobre la finca que le pareciere y fuere de su satisfacción, otorgando escritura de imposición a favor de dicha cofradía de Nuestra Señora de Guadalupe, de dicha iglesia de San Juan de la Penitencia, cuyo instrumento se entregue al mayodormo que es o fuere de ella, para que puesta en el archivo se perpetúe el derecho a dicho principal de censo y los réditos de él, que son diez pesos, con ellos quiero y es mi voluntad, que el dicho mi hijo don Pedro de Zúñiga y Rivero, tenga y sea a su cargo el cuidado de que anualmente se cante una misa en el altar de dicha cofradía de Nuestra Señora de Guadalupe, el último día de la novena que se acostumbra hacer a su majestad, y si dicha novena no tuviere perseverancia, se diga y cante dicha misa el mismo día de nuestra Señora y de su aparición, antes de la fiesta de dicha cofradía, costeándose dicha misa y seis velas de a media libra de los diez pesos de réditos, y fallecido que sea el dicho don Pedro, mi hijo, pase el cuidado de mandar decir la misa en la forma que va referido, al mayordomo que fuere de ella, para su perpetuidad, que así es mi última y deliberada voluntad. $Y$ si acaso el dicho don Pedro, antes de mi fallecimiento me diere y pagare los expresados cientos que paran en su poder procederé yo a la imposición de dicho censo para los mencionados efectos, de que se hallará razón, por mi puesta, al pie del tanto que se me diere de este mi testamento, para que así conste y si no se hallare razón de haberlos impuesto, se saquen de mis bienes los otros cien pesos, para que se haga como llevo dispuesto.

Item. Quiero y es mi voluntad, se manden decir veinticinco misas a la pitanza ordinaria, por mi alma y demás de mi intención.

Item. Declaro paran en mi poder unas pulseras que se compone cada una de veinte hilos de medio rostrillo, sin manillas, las cuales pertenecen a doña Xaviera de Avila, doncella, que será de edad de catorce años, poco más o menos, hija legítima de don Francisco de Abila Rengiso y de doña Gertrudis de Córdova, difuntos, la cual se halla en el recogimiento de San Miguel de Belem, cuyas pulseras le endonó a la susodicha el licenciado don Joseph Pardo, presbítero, con más una negrita y unas casas en la plazuela de San Juan, las cuales habita el mismo licenciado don Joseph Pardo, en cuyo poder asimismo tiene la referida negrita y sólo para en el mío las expresadas pulseras con instrumento jurídico que así lo declara, las cuales he conservado en mi poder hasta tanto que la susodicha tome estado, declárolo para. que conste.

Item. Declaro que lo que yo debo y a mi me deben, sus cantidades y personas constan las que son por libro de cuentas que para en mi poder, ordeno se cobre lo uno y se pague lo otro, que así es mi voluntad.

Item. Declaro por mis bienes los que se hallaren en la casa de mi morada al tiempo de mi fallecimiento y constaren a mis albaceas. $Y$ para guardar, cumplir y ejecutar este mi testamento y lo en él contenido, dejo y nombro por mis albaceas a doña Inés de Córdova mi esposa y por tenedora de bienes a don Pedro de Súniga y Rivero mi hijo y a Juan Rodríguez Juárez mi primo, maestro asimismo del arte de pintor, a los tres juntos y a cada uno in solidum y les doy el poder y facultad que de derecho se requiera y sea necesario, para que usen de este cargo según él. 
$Y$ en el remaniente que quedare de todos mis bienes, derechos y acciones que en cualquiera manera me toquen y pertenezcan, instituyo y nombro por mi única y universal heredera a doña Inés de Torres, mi hija legitima y de la dicha mi mujer, para que lo que así fuere lo haya, goce y herede con la bendición de Dios nuestro Señor y la mía.

$Y$ por el presente revoco, anulo y doy por nulos, de ningún valor ni efecto, otros y cualesquiera testamentos, codicilos, poderes para testar y otras últimas disposiciones que antes de éste haya hecho, por escrito, de palabra o en otra forma, para que no valgan ni hagan fe judicial, ni extrajudicialmente, salvo el presente que ahora otorgo y quiero se guarde, cumpla y ejecute por mi última, final y deliberada voluntad, o por aquello que mejor en derecho lugar haya. Que es hecho en la ciudad de México, en 13 de octubre de 1722 años. $Y$ yo el escribano doy fe conozco al otorgante que, a lo que notoriamente parece, está en pie, aunque con algunos achaques habituales, en su entero juicio, cumplida memoria y entendimiento natural.

Y así lo otorgó y firmó, siendo testigos, el licenciado don Joseph Francisco de la Vega y Mendoza, presbítero de este arzobispado, abogado de esta Real Audiencia y capellán del convento de religiosas de Regina Coeli, Francisco Xavier de Lora Camacho, Joseph Flores, Joseph Chacón y Antonio de Salinas, vecinos de esta ciudad.

\author{
Antonio de Torres [rúbrica] \\ Ante mí \\ Phelipe Muñoz de Castro \\ escribano real [rúbrica]
}

\title{
INVENTARIO DE BIENES
}

Memoria de los bienes que entrego [yo María de Millán], los cuales dejó mi esposo don Antonio de Torres, por no haberse hallado memoria en el testamento, los cuales se hallan en la casa que murió. $Y$ para descargo de mi conciencia es lo siguiente:

Un armario con sus avios de pintura.

Tres escritorios con los avíos y herramienta.

Una mesa grande con un cajón con libros.

Doce paquetes de oro falso.

Otra mesa con su cajón, con estampas viejas.

Dos cajas, la una con un poco de cotense y albayalde de Castilla, la otra con tres cortinas, un cielo de cama y unos trapos viejos.

Un escritorio prieto vacío.

Un estante con unos santos de bulto que son de los indios, con unos lienzos que están debajo del mismo estante, con un san Francisco de bulto grande, que está encima de dicho armario.

${ }^{7}$ Archivo de Notarías, Cd. de México, Not Felipe Muñoz de Castro, Libro 2577, fs. 275.278v. 
$Y$ otros santos que son de dichos indios marchantes, por donde consta en los libros de cuentas que dejó dos, uno de los españoles y el otro de naturales.

Dos pantallas doradas, las cuales no se valuaron.

Más cuatro sillas de brazos.

Dos mesitas chicas y ocho taburetes con cuatro banquitos de tres pies y cuatro caballetes.

Cajita de colores al temple.

Una mesa grande donde están las piedras de moler que son seis y tres muletas.

Una caja vieja amarrada con mecate, con el albayalde que está en la valuación y encima un cajón de tierra parda.

"Más tres mesas de $\cdot$ los dichos escritorios.

Un cajón con perfiles.

Un cajoncito con pinceles viejos y alcayatas de los caballetes.

Dos varas de medir.

Tres reglas y otros palitos del ejercicio.

En dicho estante hay dos tablas de santos en blanco.

Un cesto que está debajo de una mesa con piedras pómez.

Dos cajoncitos con palitos viejos.

Un tompiate con dos manojos de cola y unas tablitas con santos viejos y más palitos que se hallarán.

En la caballeriza dos cajas viejas, una con botijas vacías y la otra vacía y sin chapa y juntamente unos tableros que son del colateral de unos indios, como se verá en el libro, que dicho colateral se halla en casa del dorador que vive en la calle que llaman de Chiconautla.

En dicha caballeriza están unos bastidores con unas tablas y otros trastecitos.

Mas en el patiecito tres escaleras con unos bastidores y ollas de aparejo.

Mas en el zaguancito un estante con dos santos viejos y unas peanas y con ellos unos troncos largos y morillos y trastes de pintura.

Mas en el cuarto de la cocina unos Cristos en blanco, una tarima vieja y unos lienzos enrollados que son de dicho colateral.

Mas en la cocina dos trastecitos viejos que son dos tablas en unos bancos en que se ponen los platos con colladorcito [coladorcito?] de cobre.

Un machete.

Un asador.

Un picador.

Un tinajero.

Una tinaja.

Una caja del carbón.

Un garabato.

Mas en la recámara tres liencecitos que están encima de la ventana.

Una santa Bárbara de a tercia bosquejada.

Un baldoquín con sus estampas y el santo Cristo con cuatro santitos alrededor y pileta del agua bendita.

Dos candeleros de azofar chicos con tijeras de despavilar.

Unos trastes viejos en la alacena. 
Unas redomas debajo de una mess.

Una xícara de Michoacán y unas tinajitas.

Mas arriba del escritorio una señora santa Ana.

Más dos xicaritas de Michoacán.

Una cola de sacudir.

Una cuarta de cochero.

Un aya de espada con su puño de palo.

$\mathrm{Y}$ una bacinica de fierro.

Un cajoncito de badana lleno con plumas

Las celosías de las ventanas.

Las macetas.

Una necesaria.

Cinco paletas.

Un candil de cobre con seis arbotantes.

Unas balanzas con su libra de plomo. ${ }^{8}$

${ }^{8}$ A. N Cd. de M., Not. Felipe Muñoz de Castro, Libro 2587, fs. 226-228v. 


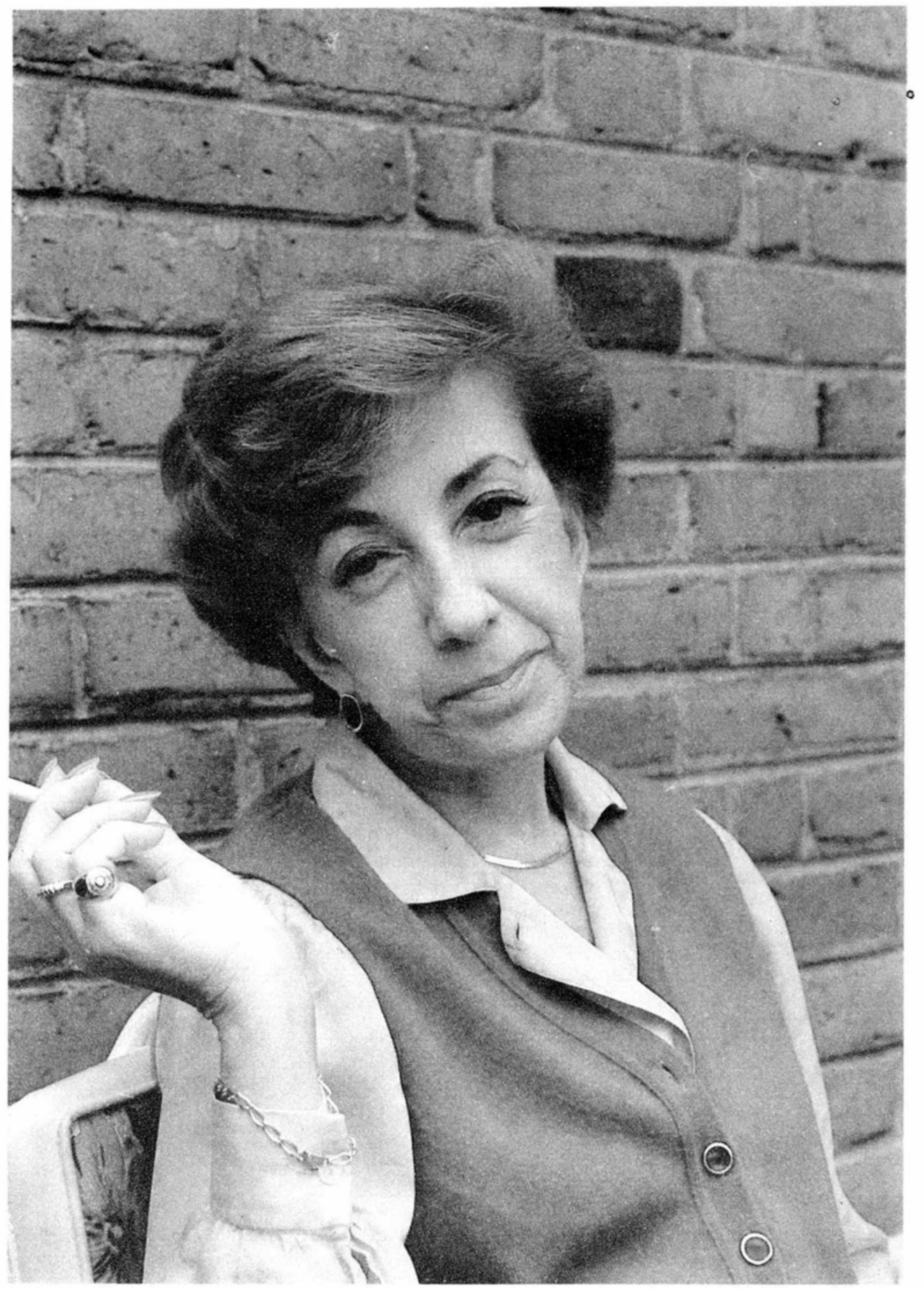

El 25 de mayo de mil novecientos ochenta y ocho falleció, en la ciudad de México, la maestra Marta Foncerrada de Molina, quien fuera, durante veintitrés años, una muy distinguida investigadora de este Instituto. 